\section{Strategy Mastery by At-Risk Students: Not a Simple Matter}

\author{
Donald D. Deshler \\ Jean B. Schumaker \\ University of Kansas Institute for Research in \\ Learning Disabilities
}

The Elementary School Journal

Volume 94, Number 2

(C) 1993 by The University of Chicago. All rights reserved. 0013-5984/93/9402-0004\$01.00

\begin{abstract}
Teachers have succeeded in teaching at-risk students, including those with learning disabilities, to master and apply complex learning strategies. The majority of this instruction has been provided in resource rooms or other remedial settings where intensive and systematic instruction has been possible. Increasingly, teachers in regular classrooms are being asked to provide learning strategy instruction to diverse classes that include students with disabilities. This expectation presents many challenges to the classroom teacher, including the creation of an instructional balance between content and strategies instruction while at the same time ensuring both the interest and growth of all students in an academically diverse class. In this article we review the results of a line of programmatic research on learning strategies instruction that has been conducted on students with learning disabilities. From this research, a set of instructional principles about how to teach learning strategies to at-risk students has emerged. These principles and implications for teaching strategies to at-risk students in regular classrooms are presented.
\end{abstract}

A prevailing trend in education today is toward the full inclusion of students with disabilities within regular schools and classrooms. For example, the Association for Supervision and Curriculum Development (ASCD) adopted as one of its 1992 "critical priority resolutions" the Full Inclusion of Special Education Programs Resolution (ASCD, 1992). Additionally, the ASCD advocated a nonlabeling approach to special populations in order to eliminate tracking and segregated services for students with unique needs. In short, this trend has the potential of markedly increasing the degree of academic and behavioral diversity in the classroom. 
Concomitant with pressures for inclusion have been other demands on classroom teachers. For example, the "Excellence in Education" movement (e.g., National Commission on Excellence in Education, 1983) has resulted in calls to increase the amount and complexity of information taught to students. Recently, the president and the governors set forth America 2000 (U.S. Department of Education, 1991), emphasizing "world-class standards" in the core subject areas. Renewed emphases on higher-order problem-solving and thinking skills (e.g., Nickerson, Perkins, \& Smith, 1985; Perkins, 1986) are based on the notion that students should be taught to be active learners who can process information independently now and in their future lives (e.g., Collins, Brown, \& Newman, 1989; Deshler \& Lenz, 1989; Pressley, Borkowski, \& Schneider, 1990).

Each of these trends forces most teachers to reexamine their posture toward the educational process. A major concern is whether addressing these demands can lead to successful and productive educational experiences for all subgroups of students, especially those who are at risk for failure. A central instructional issue is whether students with disabilities can learn complex cognitive processes within regular class environments in which considerable content is covered and world-class standards are emphasized.

Although the call for full inclusion of students with disabilities and elimination of instruction that "stigmatizes" or leads to lower teacher expectations is compelling, decisions regarding the total inclusion of students with disabilities must be made in light of salient instructional effectiveness factors and not merely issues of social acceptance. Thus, in this article we address the issue of cognitive instruction for students with disabilities in regular classrooms, emphasizing the perspective of instructional effectiveness. The framework for our discussion is a programmatic line of research on instruction of learning strategies conducted by the staff of the University of Kansas Institute for Research in Learning Disabilities (KU-IRLD).

The KU-IRLD was founded in 1977 within a climate where some educational researchers were questioning the viability of traditional approaches (e.g., remediation of basic skills) to prepare students with mild disabilities to meet the demands of the regular curriculum (e.g., Alley \& Deshler, 1979; Meichenbaum, 1977). These researchers argued that in order for students to respond to such demands successfully, they needed to be taught "how to learn" or how to use strategies.

Thus, the research and program development work of the KU-IRLD staff has focused on strategy instruction for learningdisabled and other at-risk students (e.g., Schumaker \& Deshler, 1992). From this work, the Strategies Intervention Model (SIM) (Deshler \& Schumaker, 1986, 1988) has emerged. The model is based on a set of instructional guidelines and principles which, when implemented, significantly affect the mastery of cognitive strategies and increase academic success for students with disabilities.

\section{The Foundation of KU-IRLD Strategy Instruction}

The following attributes characterize strategy instruction within the SIM. First, KUIRLD researchers have created learning strategies that are comprehensive "strategy systems" for approaching the complex learning tasks encountered in regular classrooms. Each strategy system is a collection of simple strategies integrated into one selfinstructional routine that a student can use to fulfill a class requirement (Deshler \& Lenz, 1989). One example of a strategy system is the FIRST-Letter Mnemonic Strategy (Nagel, Schumaker, \& Deshler, 1986), which includes strategies for reviewing written information, finding important information through the use of "clues" (e.g., bold-faced headings or words, diagrams, italics), creating lists of related information, 
creating memory devices to enhance recall of the items in the lists, and memorizing those lists in preparation for a test.

Second, to ensure the acquisition and generalization of learning strategy usage, students are taught to use the various cognitive and behavioral components of each strategy. The instruction systematically moves through an eight-stage process, called the SIM Instructional Methodology, which begins with heavy emphasis on an interactive process that is guided by the teacher (focusing on discussions of rationales for the use of the strategy, specification of strategy components, and explicit models by the teacher) and proceeds to an emphasis on student mediation of the learning process (Ellis, Deshler, Lenz, Schumaker, \& Clark, 1991).

During the various practice stages of strategy mastery (which include verbal practice of the strategy steps and guided and independent practice of strategy usage), teachers provide students with elaborated feedback (Kline, Schumaker, \& Deshler, $1991)$ on the quality of their work. Instruction during practice is characterized by a heavy emphasis on student mastery, for when students fail to reach mastery during the acquisition stages of instruction, there is a low probability that they will be able later to use the strategy generatively in a fluent and flexible fashion. Instruction also emphasizes generalization and maintenance. Students learn to use the strategy in a variety of settings and with respect to a variety of instructional tasks; they also learn to adapt it to fit their needs; and they review their use of it regularly.

The SIM Instructional Methodology is intended to provide a basic structure to both students and teachers to guide the learning process. The eight instructional stages are not to be applied in a rote, mechanical fashion; rather, instruction must be implemented in a way that is sensitive to the unique needs of students as well as to the classroom demands they are facing. When strategies are properly taught, students are encouraged to construct effective and personalized ways of attempting to solve academic problems. In essence, strategies that are initially presented by teachers are to be viewed as "blueprints" or exemplars of alternative ways to solve problems. They also serve as a good point of departure for stimulating dialogue between the teacher and students about "learning how to learn." This dialogue initially can consist of an examination of current learning habits and students' feelings toward learning. Later, teachers can engage students in discussions of such topics as what features of a given strategy seem to increase students' effectiveness as learners and what elements need to be altered to address different types of learning situations.

Essentially, the constructivist elements of good strategy instruction emphasized by Pressley, Harris, and Marks (in press) have been built into the instruction to promote the successful mastery and generalization of strategies. Specifically, teachers who follow the process: (a) introduce only a few strategies at a time, $(b)$ teach and promote practice of a strategy over an extended time, (c) frequently and extensively model the strategy in conjunction with ample verbal explanations and collaborative discussions to encourage flexible strategy applications, (d) use scaffolded instruction to capitalize on students' strengths and to support them during the acquisition process, and (e) acknowledge that learning is an affective, emotional process and, as such, that students' feelings and emotions should be carefully considered during the acquisition of new learning strategies. Consistent with Pressley et al.'s (in press) perspective, strategy instruction is an interactive process in which students are encouraged to carefully observe the model provided by the teacher and then flexibly adapt the model to their needs. SIM instruction provides a foundation on which students expand. Without this foundation, many students would acquire strategies inefficiently at best. 
The SIM Instructional Methodology is both an intensive and extensive approach for instructing at-risk students (Ellis et al., 1991). Explanations and models provided by the teacher make students aware of the purpose of the targeted strategy system and the advantages of using it. More important, because the dialogue throughout this type of strategy instruction requires students to be engaged actively with the teacher, this instructional process tends to create empowered learners. Thus, students are better able to deal successfully with the demands of regular class environments cognitively, behaviorally, and emotionally.

\section{KU-IRLD Strategies Research}

The strategy systems and the instructional methodology we have described have been developed through a programmatic line of research on learning strategy instruction that spans the last 13 years of KU-IRLD's existence. Within this line of research, a group of studies has been conducted in secondary special education settings. We first review these studies and their results briefly because they are reviewed elsewhere (Schumaker \& Deshler, 1992). Next, additional studies that have been completed in regular secondary classrooms, elementary special education classes, and regular elementary classrooms will be reviewed. This body of research has increased enormously our understanding of how to teach at-risk students to use learning strategies productively and generatively.

\section{Secondary Special Education Studies}

Fourteen studies have been conducted in special education settings, predominantly resource rooms (e.g., Clark, Deshler, Schumaker, Alley, \& Warner, 1984; Ellis, Deshler, \& Schumaker, 1989; Hughes \& Schumaker, 1992; Lenz \& Hughes, 1990; Schmidt, Deshler, Schumaker, \& Alley, 1989; Schumaker, Deshler, Alley, \& Denton, 1982). In all of these investigations, adolescents have been taught one or two learning strategies using the SIM Instruc- tional Methodology. In most of the studies, students with learning disabilities (LD) participated; in one study (Hughes, Deshler, Ruhl, \& Schumaker, in press), students with behavioral disorders (BD) participated. Multiple probe designs, a variation of the multiple baseline design in which infrequent test probes are used instead of daily measures (Horner \& Baer, 1978), were used in each of the studies. In some studies, a multiple-baseline-across-students design was used; in others, different learning strategies served as the baselines.

The secondary students in these studies, all of whom received intensive instruction of learning strategies, mastered the strategies and generalized them to tasks that are comparable to tasks they would encounter in regular classes. Often, when students applied the strategies they learned, their academic performance improved dramatically on the regular-class tasks. In addition, students taught in this manner generalized their use of strategies from special education to regular-class settings and maintained their use of the strategies over time and even into the next school year (Hughes et al., in press; Hughes \& Schumaker, 1992; Schmidt et al., 1989).

Finally, research has shown that strategies instruction for these types of students may increase achievement (Schumaker, Deshler, Alley, \& Warner, 1983). When the achievement test scores on the WoodcockJohnson Psychoeducational Battery (Woodcock \& Johnson, 1989) of the students with disabilities enrolled in a high school learning strategies program were compared to scores of students enrolled in two traditional resource room programs in a neighboring school district, results showed that the students who received the strategy instruction made gains of greater than 1 year of achievement in three academic areas (reading, math, and writing), whereas students in the other programs made similar gains in only one area.

The school district that originally participated in this research has now been im- 
plementing strategy instruction for about 17 years for LD students and other low achievers. A scope and sequence of strategy instruction has been in place in this district across the secondary grades (7-12) for about 6 years for LD students and other atrisk students. Teachers report that the majority of LD students are totally mainstreamed by their junior year in high school and need only occasional monitoring. They also report that the dropout rates have been reduced dramatically between the ninthand tenth-grade years for at-risk students who participate in the program (Karen Lyerla, personal communication, August 24, 1990).

In summary, LD students can master learning strategies and can apply them to tasks that are similar to those assigned in regular mainstream classes. They do so in a generative way when the instruction is intensive and requires mastery performance.

\section{Regular Secondary Classrooms}

Two studies have been conducted in regular secondary classes in which LD students were mainstreamed. The first study (Beals, 1983) was conducted in three regular high school English classes, in each of which three students with LD were enrolled. The Sentence Writing Strategy (Schumaker \& Sheldon, 1985), a strategy for conceptualizing and writing sentences, and the Error Monitoring Strategy (Schumaker, Nolan, \& Deshler, 1985), a strategy for finding errors in one's writing, were taught to Class A; the Paraphrasing Strategy (Schumaker, Denton, \& Deshler, 1984), a strategy for translating the main idea and details of a passage into one's own words, and the Self-Questioning Strategy (Clark et al., 1984), a strategy for asking oneself questions while reading, were taught to Class B; and Class $C$ received regular English instruction. A multiple-probe design and a comparison-group design were used.

The strategy instruction replaced the regular English curriculum in Classes $\mathrm{A}$ and
B during the course of the study. A special education teacher taught the writing strategies along with the regular English teacher in Class A. The regularly assigned English teachers taught Classes B and C. In Classes $A$ and B, the SIM Instructional Methodology was used with the addition of cooperative group structures for practice activities. Students were assigned to groups of four students, each comprised of one LD student or a low-achieving student, two average-achieving students, and a highachieving student, based on current grades in the class.

All students completed each practice activity individually, but they could seek help from any member of their group. After receiving a feedback sheet from the teacher on the results of the previous day's practice activities, students provided instruction to each other related to errors on prior assignments before the next day's practice activity began. Individual grades depended on group as well as individual performance. Each student in the class was required to master the strategy being taught.

Students with LD and their peers in the class mastered the strategies at rates and levels comparable to students who had participated in similar studies conducted in resource rooms. Although the LD students did not maintain their use of the writing strategies at posttest levels after instruction and feedback were terminated, they were still writing more complete and complex sentences than they had during the pretest condition. Students who learned the reading strategies maintained or exceeded their posttest scores on three of the five reading measures. Similar maintenance results were achieved for the low-achieving students. The high achievers maintained their posttest scores.

The students with LD were generally satisfied with the instruction; however, the high-achieving students in the class were not. Throughout the study, the high achievers felt "used" and did not want to participate as the other students' instructors. Al- 
though the teacher of Class A was satisfied with the procedures and the strategies, the teacher of Class B was not. Even though the teacher of Class A regarded writing instruction to be a legitimate part of the regular English curriculum, she stated that the students should have mastered the skills earlier than in the tenth grade. The teacher of Class $B$ regarded reading instruction to be outside of her high school English curriculum. Thus, even though the students had not mastered basic writing skills and reading comprehension skills, neither teacher was satisfied with teaching the particular strategies targeted for the study. Both teachers indicated that the grading and feedback procedures (which required the teachers to grade daily practice attempts and prepare feedback) were unwieldy and impractical.

Thus, although strategy instruction can be successful in regular classrooms with heterogeneous groups of students through the use of cooperative group structures, consideration needs to be given to the tradeoffs made with regard to the content being taught, practicality of the procedures, and high-achieving students' satisfaction with the procedures. The latter issue raises special concern in light of secondary regularclass teachers' reports that they discard any instruction that the high-achieving students in their classes dislike (Lenz, Schumaker, \& Deshler, 1991).

In a more recent study conducted in regular secondary social studies classrooms (Scanlon, Deshler, \& Schumaker, 1993), teachers taught heterogeneous classes (including students with LD) the ORDER Strategy, a strategy for reflecting on information that has been presented/discussed in class, choosing an organizational structure for that information, creating an organizational diagram of the information, and studying the information. This strategy was designed after discussions with participating social studies teachers indicated that they would value teaching a strategy that would help students organize and study social studies information. The teachers also indicated that they would be willing to spend about $10 \%$ of class time per week (or about 25 minutes per week) teaching such a strategy. They also indicated that they were not willing to replace content instruction with strategy instruction; the strategy instruction would have to be integrated with their content instruction for the strategy instruction to be acceptable to them.

In order to meet these requirements, an adaptation of the SIM Instructional Methodology was developed for this study. Teachers introduced the strategy to the students by describing it conceptually and procedurally. Demonstrations of use of the strategy were interspersed within the usual social studies instruction, as were practice activities. Teachers used combinations of guided whole-class activities, cooperative group activities, and individual practice activities depending on their individual preferences; however, each student was to practice using the strategy individually. Students were exposed to some phase of strategy instruction about once a week for about 7 weeks.

At first, the teachers were not given any criteria for judging whether students had mastered the strategy. None of the teachers created criteria for this purpose. Two of the first three teachers to begin instruction in the study indicated that they were ready to move on to a new strategy before they had conducted individual practice activities. When individual practice samples were collected from the students of these teachers, the majority of the students in their classes had not mastered the strategy.

After the teachers were given criteria by which they could judge whether students had mastered the strategy, they continued the practice stage of instruction. Overall, the results of the study showed that students in experimental classes performed significantly better than students in comparison classes $(p<.0005)$, and LD students in experimental classes performed significantly better than LD students in comparison classes $(p<.02)$ on a test requiring students 
to create an organizational diagram of written information. Unfortunately, when individual test performances were evaluated, only five of the 11 LD students in the experimental classes created appropriate diagrams; six did not. Likewise, some of the NLD students in experimental classes also did not create appropriate diagrams. Nevertheless, all subgroups of students in the classes (LD, low achievers, and high achievers), as well as the teachers, indicated that they were generally satisfied with the strategy instruction.

Clearly, teachers of heterogeneous classes need objective, but practical, methods for determining whether their students have learned a strategy. They also need methods for facilitating the learning of all students in their classes, including LD students. In short, teaching a strategy within the context of content instruction (e.g., in conjunction with the delivery of social studies content) in large classes in which heterogeneous groups of students are enrolled is different from teaching a strategy in a class where strategy instruction is the main focus.

\section{Elementary Special Education Settings}

Two studies have been conducted in elementary special education settings. In the first, as a part of a larger study including both secondary and elementary classrooms (Kline et al., 1991), elementary resource room teachers taught their students the Sentence Writing Strategy (Schumaker \& Sheldon, 1985). The focus of the study was a comparison of three feedback procedures used by three groups of teachers: (a) a standard feedback procedure whereby students were informed of what they had done well and what they had done incorrectly; $(b)$ an elaborated feedback procedure requiring teachers also to categorize each student's errors, communicate those categories to the student, create with the student ministrategies for avoiding future errors, and provide models and supervised practice of the ministrategy; and (c) the elaborated feed- back procedure combined with active student participation in the procedure (as prompted by the teacher) and goal setting for future performance.

The three feedback procedures were added to the SIM Instructional Methodology described earlier. For the elementary students, the lessons were shortened, and the number of responses students had to make on a given practice attempt was reduced. The elementary students learned the components of the strategy as well as the secondary students. In some instances, the elementary students required significantly fewer trials to mastery than the secondary students $(p<.05)$. Indeed, the elementary students made more improvement across two practice trials than the secondary students who had the same feedback procedures; however, the elementary students also made more initial errors. The elementary students responded like the secondary students with regard to the different kinds of feedback; that is, students who were given the elaborated types of feedback required significantly fewer trials to mastery than students given standard feedback ( $p<$ .05 and $p<.001$ depending on the lesson).

In the second study conducted in a special-class setting, Eland (1990) taught six sixth graders with reading problems the Visual Imagery Strategy (Schumaker, Deshler, Zemitzsch, \& Warner, 1993), a strategy for creating visual images as one reads, using a case-study format. The students mastered the strategy quickly, and all experienced gains in reading comprehension when they used the strategy. Furthermore, they maintained their use of the strategy at posttest levels 10 days after instruction was terminated.

Thus, elementary as well as secondary students benefit from strategy instruction. In some cases, elementary students appear to learn the strategy faster and achieve better results than older students. Teachers who worked with the students hypothesized that elementary students do not bring as much "baggage" (e.g., a history of fail- 
ure, dysfunctional beliefs about learning) with them to strategy instruction as do secondary students and are thus more amenable to the instruction.

\section{Regular Elementary Classrooms}

Two other studies have been completed in regular elementary classrooms. In one, conducted by Wedel, Deshler, Schumaker, and Ellis (1993), a heterogeneous group of sixth-grade students (including six students with LD) was taught the LINCS Strategy (Ellis, 1992) in their regular classroom by the special education teacher. The LINCS Strategy was designed to enable students to learn the meaning of new vocabulary words through the use of three types of memory devices: visual imagery, key words, and linking stories. The basic elements of the SIM Instructional Methodology were used. Strategy instruction replaced a portion of the time normally allotted for English for 5 weeks. The total instructional time allotted to social studies content instruction remained constant during preexperimental and experimental conditions; only the method of instruction for vocabulary was changed. Students in a comparison class received the same social studies instruction as those in the experimental class, from the same teacher. In addition, they made a study card for each vocabulary word in class and were given time to study the cards.

All students in the experimental class mastered the use of the strategy within about 3 weeks. Additionally, they made substantial mean score gains across pre- and postintervention social studies vocabulary tests $(75 \%$ vs. $88 \%)$, whereas the comparison class (which had no LD students enrolled) made no gains ( $86 \%$ vs. $85 \%$ ). In the experimental class, the LD students' mean score on the preinstruction vocabulary test was $53 \%$ and their score on the postinstruction vocabulary test was $77 \%$. In the same class, the non-LD students' mean score on the pretest was $84 \%$ and on the posttest was $92 \%$.
However, Wedel et al. (1993) noted that some of the LD students required more time than allotted for the strategy instruction in the regular class. Although they were able in the allotted time to create their own memory devices and to make study cards, they did not have enough time to commit the information to memory. Thus, additional time for memorization was provided in the resource room. Otherwise, the students with $L D$ received the same instruction and required about the same number of practice attempts before reaching mastery as the other students in the class.

In the second study in the regular elementary classroom, three sixth-grade teachers taught their students a paraphrasing strategy called "TAPE" (Lenz, Boudah, Schumaker, \& Deshler, 1993). When using this strategy, students "tune in" to the content being presented, ask themselves questions about the content, paraphrase the content through rephrasing and summarizing, and elaborate on the content. The instructional methods were similar to those used with the ORDER Strategy; that is, teachers informed students about the strategy, modeled its use, and combined an assortment of practice activities with regular content instruction. Typically, teachers prompted use of the strategy by reminding students to "tune in" and by asking them questions during class discussions that required them to rephrase, summarize, or elaborate on the content that had been presented or read.

A comparison-group design was used. The students without disabilities in the experimental classes made significant gains with regard to rephrasing information. No gains were made with regard to summarizing content and elaborating on content. Students with LD made no gains in any of the areas, however. This may be due to the fact that the LD students had few opportunities to practice using the strategy. Teachers rarely prompted these students to rephrase, summarize, or elaborate in class (e.g., one teacher gave her LD students approximately .4 prompts per student per observed 1-hour 
session). The rates at which other students were prompted to practice elements of the strategy were also low (between 6 and 16 prompts per observation for the entire class).

In sum, strategy instruction might be successful in regular classrooms if certain conditions are met. Namely, instruction must be systematic and intensive. If necessary, at-risk students must receive additional time to complete practice activities. Some important conditions seem to delimit the successful instruction of learning strategies with at-risk students in regular classrooms: high-achieving students might become bored when additional instructional time is set aside for low achievers to master the strategy, classroom teachers spend little of their instructional time on strategy instruction, regular teachers tend to provide few prompts and practice opportunities to low achievers when teaching strategies to the class, and teachers may have difficulty integrating strategies instruction into the existing classroom routine. Although there are some encouraging signs that at-risk students can successfully master strategies in the regular classroom, strategy instruction in the context of content instruction has not been as successful as the intensive strategy instruction that generally takes place in special education settings.

\section{Attributes of Mainstream Strategy Instruction}

A number of attributes of instruction have become apparent through the course of conducting the research we have described that have some bearing on whether strategy instruction can be successful in the regular classroom for at-risk students, including students with disabilities.

\section{Instructional Goals Must Include} Strategy Learning

First, a consensus by both educators and students must exist with regard to the instructional goals that are valued for at-risk students in the regular classroom. Mini- mally, these should include (a) student acquisition of an enhanced knowledge base that leads to cultural and scientific literacy (e.g., Graff, 1987), and (b) student acquisition of the skills related to being a "good information processor" (i.e., being able to approach tasks and solve problems in a strategic fashion; Pressley et al., 1990). Unless educators value the goal of student acquisition of strategies, they will not devote the necessary instructional time, nor will they put the necessary emphasis on strategic instruction and other process-related activities. Likewise, if students do not value the goal of becoming "good information processors," they will not invest the effort required to learn strategies and related knowledge. Thus, involving students actively in the goal-setting and assignment-selection process is an important element in ensuring that students "buy into" the educational processes associated with this goal. When students are involved in planning and goalsetting, they gain the perception of control and influence over their own learning ( $\mathrm{Ra}$ demacher, 1993; Van Reusen, Deshler, \& Schumaker, 1989) and are willing to put their time and energy into learning.

Strategy Instruction Must Be Integrated with Content Instruction

When teachers see their role as a "strategic-content" teacher as opposed to a "content" teacher, they present strategy instruction in a sustained fashion, thus ensuring that at-risk students as well as others in the class receive more consistent exposure to instruction in "how to learn" than they would during traditional instruction (Deshler \& Schumaker, 1990). If strategies are taught in conjunction with mainstream content, students also can see relationships between content elements and the learning processes being used. Learning particular strategies will be more relevant for them.

Clearly, the role of the strategic-content teacher is significantly expanded over the role of the conventional classroom teacher and, in turn, the knowledge that is needed 
in order to teach students is also expanded. Among the different competencies teachers need in this new role are the following. First, they need knowledge of task-specific learning strategies that will enable students to process information, including strategies that facilitate acquiring, organizing, memorizing, retrieving, and expressing information. Second, teachers need knowledge of metacognitive (control) strategies that students can use to plan, monitor, select, and evaluate their application of task-specific strategies. Third, they need knowledge of the kinds of information that students must learn in order to use strategies effectively, such as declarative information (i.e., what the components of the strategy are), procedural information (i.e., how to apply the strategy), and conditional information (i.e., when and where to use the strategy) (Ellis et al., 1991). Fourth, teachers need knowledge about what strategies are appropriate in light of a specific curricular demand or in conjunction with certain types of content and how each strategy can be adapted to different learning situations. Finally, teachers need to be able to communicate this knowledge to students clearly and in ways that enable students to understand and remember the information.

\section{Strategy Instruction Must Be Based on} Sound Principles

A third attribute of successful strategy instruction is that it must incorporate those elements that promote strategy mastery. These elements must enable teachers not only to teach a strategy but also to monitor student progress with regard to learning the strategy and to determine the overall effectiveness of strategy usage by their students. The number and quality of opportunities that students are given to witness strategies being used by others, to practice using strategies themselves, and to generalize their use of strategies to different circumstances and settings are critical.

In short, the manner in which strategies are taught to students, especially students with disabilities, can significantly affect the degree to which students actually change as learners. As described earlier, KU-IRLD research has shown that LD students have readily been able to achieve mastery of a targeted strategy if the instruction is systematic and intense. Successful strategy instruction is not necessarily the result of where students are placed but rather a result of the instructional conditions that are present in the learning setting. Research has repeatedly shown that at-risk students can acquire and generalize task-specific learning strategies when certain instructional principles are operationalized. These principles are briefly described here. (For a more thorough explanation see Ellis et al., 1991.)

Principle 1: Teach prerequisite skills before strategy instruction begins. Because most learning strategies are designed to enable students to use skills in a problemsolving context, skills required for successful strategy use should be mastered before instruction in the actual strategy begins. Teaching the necessary prerequisite skills prior to strategy instruction enables students to benefit more fully from instruction in a given strategy, and it allows students to travel a relatively straight and uninterrupted path between the initial introduction and description of the strategy and the actual application of the strategy to classroom assignments. For example, if students have learned the skill of identifying nouns and verbs before receiving instruction in the Sentence Writing Strategy (Schumaker \& Sheldon, 1985), they will be able to quickly learn a cognitive process for monitoring whether their sentences are complete.

Principle 2: Teach regularly and intensively. For LD students to successfully master complex learning strategies to a point of fluency, they need frequent and consistent instruction. Ideally, this means daily strategy instruction with ample opportunities for practice programmed each day. Teachers' and students' setting of daily, weekly, and semester goals related to strategy acquisition can also enhance the intensity of 
instruction and facilitate strategy acquisition.

Principle 3: Emphasize personal effort. Successful problem solving, in the simplest terms, is related to (a) choosing a strategy that can effectively address the demand that has been encountered and then $(b)$ trying as hard as possible to use the strategy properly. Reminding students regularly that academic success results when they put forth significant personal effort in applying an appropriate learning strategy to a task is important.

Principle 4: Require mastery. Research has shown that students are more likely to generalize their use of a given learning strategy (the major instructional goal) when they can perform the strategy proficiently (Schmidt et al., 1989). Thus, after students acquire a basic understanding of the intent and steps of a given strategy, they must have a chance to increase the speed and fluidity with which they can use the strategy. Pressley, Johnson, and Symons (1987) argue that the strategy must be integrated into students' repertoires at the automatic level. Clearly, finding the necessary instructional time to help students arrive at a point of fluent use of a strategy through independent practice with content materials is a challenge. Not only must students be given ample opportunities to use a strategy, they must also be given pertinent and elaborated feedback as they practice. This feedback is especially critical for at-risk students, sometimes cutting required learning time in half (Kline et al., 1991).

Principle 5: Emphasize covert processing. Throughout instruction, teachers need to deliberately discuss and demonstrate the covert processes involved in performing the targeted strategy. Students often are unaware of basic cognitive strategies such as visual imagery, self-questioning, prioritizing, hypothesis generating, or paraphrasing and metacognitive strategies such as problem analysis, decision making, goal setting, task analysis, and self-monitoring. As part of their direct explanation model of instruc- tion, Roehler and Duffy (1984) argue that effective teachers focus not only on the mechanical aspects of learning and performing but also on teaching students to understand and use the covert processes involved in academic tasks.

Principle 6: Emphasize generalization in the broadest sense. Over time, the focus of instruction should shift from teaching students to use a task-specific learning strategy to meet the demands associated with a specific problem to a focus on how strategies can be used to address similar problems in the same or other domains. Only when instruction produces this broader application of a strategy does the strategy begin to be a useful tool. When students are encouraged to invent or adapt strategies, their ownership of strategies increases as well as the probability that they will apply the strategies across a broad array of settings and situations.

\section{Strategy Instruction Needs to Be} Adjusted to Students' Needs

A fourth factor that seems necessary for promoting strategy mastery within mainstream classrooms relates to the degree to which strategy instruction is compatible with the characteristics and needs of students. A potentially difficult instructional dilemma confronts teachers who are considering teaching at-risk students strategies in the elementary grades because these students may have skill deficits that require intensive instruction. If students' skill deficits are severe and are related to the prerequisites for specific learning strategies, abandoning the intensive skills instruction may not be justified until students have acquired those skills. For example, a thirdgrade student may still be struggling with first-grade reading materials. Such a student might not be ready for a reading comprehension strategy. Nevertheless, if younger students possess the prerequisite skills for a learning strategy, strategies instruction may be an appropriate choice. Thus, the teacher's knowledge of the prerequisite 
skills related to specific strategies and of the students' levels of skill development is important when evaluating the appropriateness of strategies instruction for a given group of students.

Additionally, younger students seem to need a slightly different type of strategy instruction than older students. Clark, Schumaker, Deshler, and Kline (1990) have outlined a set of principles that has emerged from their work with elementary teachers who adapted strategy instruction that was initially designed for secondary students to be useful for elementary students who are at risk for failure. These principles are not necessarily unique to strategies instruction with younger students; they are, however, important whenever students: (a) experience difficulty in attention or memory; (b) lack strategies that enable them to plan, execute, and evaluate their performance on a task or its outcomes; or $(c)$ require extensive guidance and monitoring during initial practice. The five principles identified by Clark et al. (1990) are: use short, 5-15-minute lessons; teach concepts in meaningful and concrete ways; provide interesting examples, analogies, and stories so as to maintain a high level of attention; conduct many guided practice activities; and ensure active student participation throughout.

\section{Instruction Must "Fit" within the}

Regular Class Milieu and Produce

Obvious Results

Classroom teachers must find preparing for strategy instruction and implementing it in conjunction with their content to be easy and practical. The instructional procedures must not only be acceptable to teachers, but they must also be acceptable to all students (high achievers as well as low achievers) (Lenz et al., 1991). Finally, the teacher and students must perceive that instruction is benefiting all students in a useful way. These requirements must be met if teachers are to be expected to continue implementing strategy instruction over time.

\section{Conclusion}

Unfortunately, although these attributes of strategy instruction for mainstream educational settings have become apparent, few, if any, instructional packages are available commercially that operationalize them. Indeed, KU-IRLD researchers are currently struggling to find the "right mix" of procedures that are not only effective in producing mastery of complex strategy systems for all students but that also are accepted by regular teachers and students.

Through this struggle, several factors that are problematic or even counterproductive to the mastery of strategies by atrisk students in regular classrooms have become apparent. First, because of the strong face validity of strategies instruction, many teachers express a willingness to incorporate it in their ongoing class routine or report that they already do spend considerable time teaching strategies (Lenz, Bulgren, Deshler, \& Schumaker, 1993). In reality, the strategy instruction that takes place in these classes tends to be less frequent than teachers report and at a low level of intensity or consistency. Clearly, at-risk students do not benefit from such superficial exposure to strategies. They do not automatically see the connections between various content demands and the use of a given strategy, nor do they effectively mediate their own instruction so as to bring themselves to mastery. The absence of systematic instruction that ensures ample practice opportunities and detailed feedback about performance leaves students short of being fluent strategy users.

Second, because teachers currently value content instruction above strategy instruction, content instruction takes precedence. As a result, teachers may introduce strategies instruction into their ongoing routine in the middle of the school year, and it may not be well accepted by students because they see the instruction as inconsistent with norms and expectations the teacher established at the beginning of the year. Once students become accustomed to being

NOVEMBER 1993 
evaluated primarily for their mastery of curriculum content, they may not exert sufficient effort or focus their attention on working toward the mastery of strategies. If students do not receive credit and grades for mastery and application of learning strategies, they tend not to take the instruction seriously. In contrast, if teachers introduce students to a dual instructional focus in their classes (i.e., content and strategies) at the beginning of the school year and emphasize that content and strategies "count," student performance can be enhanced.

Even if teachers avoid these problems, instruction of complex strategy systems may still not be effective for all students enrolled in heterogeneous mainstream classes nor acceptable to classroom teachers so that they incorporate related instruction into their routine teaching. Strategy systems need to be developed that can be integrated readily and frequently with content instruction, and instructional methods and management systems that allow for differences in student acquisition rates need to be created and validated. Once these goals have been accomplished, instructional materials need to be written and made widely available, and effective teacher training procedures need to be developed and implemented at both the in-service and preservice levels.

The idea of complex learning strategies being taught in regular classrooms in which at-risk students are enrolled is promising. Teachers have already taught simple strategies in this context to normally achieving students. In addition, the research reviewed here supports the notion that students with disabilities and other low achievers can not only learn complex strategy systems, but that they can learn them within mainstream classrooms when provided instruction based on sound principles. Unfortunately, this undertaking can be complicated by the recent emphasis on teaching increasingly more content to achieve higher standards.

Exactly how teachers can create a balance between content and strategies in- struction while at the same time ensuring both the interest and growth of low-, average-, and high-achieving students is still evolving. Certainly, the factors we have described seem central to successful mastery and application of learning strategies by atrisk students. Significant work remains in effectively integrating these principles into an instructional system that is perceived as practical by the classroom teacher and motivating to the majority of students. Finally, so that strategy instruction is not viewed as an "add-on," it needs to be designed so that it can be integrated readily into classroom instruction. Clearly, educators and researchers need to turn their attention to a careful analysis of the factors that enable low-achieving students, including those with disabilities, to master complex taskspecific learning strategies and to apply them fluently to solve problems and respond to the demands of the classroom in a generative way.

\section{References}

Alley, G. R., \& Deshler, D. D. (1979). Teaching the learning disabled adolescent: Strategies and methods. Denver: Love.

Association for Supervision and Curriculum Development. (1992). Resolutions 1992: Critical priority resolutions endorsed by resolutions committee. Washington, DC: Author.

Beals, V. L. (1983). The effects of large group instruction on the acquisition of specific learning strategies by learning disabled adolescents. Unpublished doctoral dissertation, University of Kansas, Lawrence.

Clark, F. L., Deshler, D. D., Schumaker, J. B., Alley, G. R., \& Warner, M. M. (1984). Visual imagery and self-questioning: Strategies to improve comprehension of written material. Journal of Learning Disabilities, 17, 145-149.

Clark, F. L., Schumaker, J. B., Deshler, D. D., \& Kline, F. M. (1990). Teaching younger students to master learning strategies. Lawrence: University of Kansas Institute for Research in Learning Disabilities.

Collins, A., Brown, J. S., \& Newman, S. E. (1989). Cognitive apprenticeship: Teaching the craft of reading, writing, and mathemat- 
ics. In L. B. Resnick (Ed.), Cognition and in- $\rightarrow$ Kline, F. M., Schumaker, J. B., \& Deshler, D. D. struction: Issues and agendas (pp. 127-159). Hillsdale, NJ: Erlbaum.

Deshler, D. D., \& Lenz, B. K. (1989). The strategies instructional approach. International Journal of Disability, Development, and Education, 36(3), 203-224.

Deshler, D. D., \& Schumaker, J. B. (1986). Learning strategies: An instructional alternative for low-achieving adolescents. Exceptional Children, 52(6), 583-590.

Deshler, D. D., \& Schumaker, J. B. (1988). An instructional model for teaching students how to learn. In J. L. Graden, J. E. Zins, \& M. L. Curtis (Eds.), Alternative educational delivery systems: Enhancing instructional options for all students (pp. 391-411). Washington, DC: National Association of School Psychologists.

Deshler, D. D., \& Schumaker, J. B. (1990). Validation of an integrated model of content and strategic instruction for secondary mainstream classes (Grant No. H023C10020). Washington DC: U.S. Department of Education, Office of Special Education and Rehabilitative Services.

Eland, A. D. (1990). The effect of an imagery strategy on the reading comprehension of sixthgrade students. Unpublished master's thesis, University of Kansas, Lawrence.

Ellis, E. S. (1992). LINCS: A starter strategy for vocabulary learning. Lawrence, KS: Edge Enterprises.

Ellis, E. S., Deshler, D. D., Lenz, B. K., Schumaker, J. B., \& Clark, F. L. (1991). An instructional model for teaching learning strategies. Focus on Exceptional Children, 23(6), 1-24.

Ellis, E. S., Deshler, D. D., \& Schumaker, J. B. (1989). Teaching adolescents with learning disabilities to generate and use task-specific strategies. Journal of Learning Disabilities, 22(2), 108-130.

Graff, H. J. (1987). The legacies of literacy: Continuities and contradictions in western culture and society. Bloomington: Indiana University Press.

Horner, R. D., \& Baer, D. M. (1978). Multipleprobe technique: A variation of the multiple baseline. Journal of Applied Analysis, 11, 189196.

Hughes, C. A., Deshler, D. D., Ruhl, K. L., \& Schumaker, J. B. (1993). Test-taking strategy instruction for adolescents with behavior disorders. Journal of Emotional and Behavioral Disorders, 1(3), 189-199.

Hughes, C. A., \& Schumaker, J. B. (1992). Testtaking strategy instruction for adolescents with learning disabilities. Exceptionality, 2, 205-221.

(1991). The development and validation of feedback routines for instructing students with learning disabilities. Learning Disability Quartery, 14(3), 191-207.

Lenz, B. K., Boudah, D., Schumaker, J. B., \& Deshler, D. D. (1993). Teaching students a paraphrasing strategy in conjunction with content. Manuscript in preparation. Lawrence: University of Kansas Institute for Research in Learning Disabilities.

Lenz, B. K., Bulgren, J. A., Deshler, D. D., \& Schumaker, J. B. (1993). Reports of regular classroom teachers on the "Strategy Role-Match Survey." Manuscript in preparation. Lawrence: University of Kansas Institute for Research in Learning Disabilities.

Lenz, B. K., \& Hughes, C. (1990). A word identification strategy for adolescents with learning disabilities. Journal of Learning Disabilities, 23(3), 149-158.

Lenz, B. K., Schumaker, J. B., \& Deshler, D. D. (1991, April). Planning in the face of academic diversity: Whose questions are we answering? Paper presented at the annual meeting of the American Educational Research Association, Chicago.

Meichenbaum, D. (1977). Cognitive behavior modification: An integrative approach. New York: Plenum.

Nagel, D. A., Schumaker, J. B., \& Deshler, D. D. (1986). The FIRST-letter mnemonic strategy: Instructor's manual. Lawrence, KS: Edge Enterprises.

National Commission on Excellence in Education. (1983). A nation at risk: The imperative for educational reform. Washington, DC: U.S. Department of Education.

Nickerson, R. S., Perkins, D. N., \& Smith, E. E. (1985). The teaching of thinking. Hillsdale, NJ: Erlbaum.

Perkins, D. N. (1986). Thinking frames. Educational leadership, 43(8), 4-10.

Pressley, M., Borkowski, J. G., \& Schneider, W. (1990). Good information processing: What it is and how education can promote it. International Journal of Educational Research, 2, 857-867.

Pressley, M., Harris, K. R., \& Marks, M. B. (in press). But good strategy instructors are constructivists! Educational Psychology Review.

Pressley, M., Johnson, C. J., \& Symons, S. (1987). How can good strategy use by taught to children? Evaluation of six alternative approaches. In S. Cormier \& J. Hagman (Eds.), Transfer of learning: Contemporary research and applications (pp. 71-89). Orlando, FL: Academic Press. 
Rademacher, J. (1993). The validation of a classroom assignment routine for mainstream settings. Unpublished doctoral dissertation, University of Kansas, Lawrence.

Roehler, L. R., \& Duffy, G. G. (1984). Direct explanation of comprehension processes. In G. G. Duffy, L. R. Roehler, \& J. Mason (Eds.), Comprehension instruction: Perspectives and suggestions (pp. 265-280). New York: Longman.

Scanlon, D. L., Deshler, D. D., \& Schumaker, J. B. (1993). ORDER: A strategy for reflecting upon and determining organization within classroom lectures. Manuscript in preparation. Lawrence: University of Kansas Institute for Research in Learning Disabilities.

Schmidt, J. L., Deshler, D. D., Schumaker, J. B., \& Alley, G. R. (1989). Effects of generalization instruction on the written language performance of adolescents with learning disabilities in the mainstream classroom. Journal of Reading, Writing, and Learning Disabilities, 4(4), 291-309.

Schumaker, J. B., Denton, P. H., \& Deshler, D. D. (1984). The Paraphrasing Strategy: Instructor's manual. Lawrence: University of Kansas Institute for Research in Learning Disabilities.

Schumaker, J. B., \& Deshler, D. D. (1992). Validation of learning strategy interventions for students with learning disabilities: Results of a programmatic research effort. In B. Y. L. Wong (Ed.), Contemporary intervention research in learning disabilities: An international perspective (pp. 22-46). New York: SpringerVerlag.

$\rightarrow$ Schumaker, J. B., Deshler, D. D., Alley, G. R., \& Denton, P. H. (1982). Multipass: A learning strategy for improving reading comprehension. Learning Disability Quarterly, 5(3), 295304.

Schumaker, J. B., Deshler, D. D., Alley, G. R., \& Warner, M. M. (1982). Error Monitoring: A learning strategy for improving LD adolescent performance. In W. M. Cruickshank \& J. W. Lerner (Eds.), The best of $A C L D$ (Vol. 3, pp. 170-183). Syracuse, NY: Syracuse University Press.

Schumaker, J. B., Deshler, D. D., Alley, G. R., \& Warner, M. M. (1983). Toward the development of an intervention model for learning disabled adolescents. Exceptional Education Quarterly, 3(4), 45-74.

Schumaker, J. B., Deshler, D. D., Zemitzsch, A., \& Warner, M. M. (1993). The Visual Imagery Strategy: Instructor's manual. Lawrence: University of Kansas Institute for Research in Learning Disabilities.

Schumaker, J. B., Nolan, S. M., \& Deshler, D. D. (1985). The Error Monitoring Strategy: Instructor's manual. Lawrence: University of Kansas Institute for Research in Learning Disabilities.

Schumaker, J. B., \& Sheldon, J. (1985). The Sentence Writing Strategy: Instructor's manual. Lawrence, KS: Edge Enterprises.

U.S. Department of Education. (1991). America 2000: An educational strategy. Washington, DC: Author.

Van Reusen, A. K., Deshler, D. D., \& Schumaker, J. B. (1989). Effects of a student participation strategy in facilitating the involvement of adolescents with learning disabilities in the individualized educational program planning process. Learning Disabilities, 1(2), 23-34.

Wedel, M., Deshler, D. D., Schumaker, J. B., \& Ellis, E. S. (1993). Effects of applying a keyword memory strategy within academically diverse regular classrooms. Unpublished manuscript. Lawrence: University of Kansas Institute for Research in Learning Disabilities.

Woodcock, R. W., \& Johnson, M. B. (1989). Woodcock Johnson Psychoeducational Battery: Tests of Achievement. Allen, TX: DLM Teaching Resources. 